\title{
Customer loyalty among daily disposable contact lens wearers
}

Neelam I. Patel MOptom MCOptom ${ }^{1,2}$, Shehzad A. Naroo MSc, PhD, FCOptom ${ }^{1}$, Frank Eperjesi MBA, PhD, FCOptom ${ }^{1}$ \& Nicholas J. Rumney MScOptom, FCOptom ${ }^{2}$

1. School of Life and health Sciences, Aston University, Birmingham, B4 7ET

2. BBR Optometry Ltd, Hereford, HR1 2PR

Corresponding Author: Dr Shehzad A. Naroo

Email: s.a.naroo@aston.ac.uk

Telephone: +44(0)121 2044142

Fax: +44 (0)121 204 4048: 


\section{Abstract}

Background: Optometric practices offer contact lenses as cash sale items or as part of monthly payment plans. With the contact lens market becoming increasingly competitive, patients are opting to purchase lenses from supermarkets and Internet suppliers. Monthly payment plans are often implemented to improve loyalty. This study aimed to compare behavioural loyalty between monthly payment plan members and non-members.

Methods: BBR Optometry Ltd offers a monthly payment plan (Eyelife ${ }^{\mathrm{TM}}$ ) to their contact lens wearers. A retrospective audit of 38 Eyelife $^{\mathrm{TM}}$ members (mean \pm SD: $42.7 \pm 15.0$ years) and 30 non-members (mean \pm SD: $40.8 \pm 16.7$ years) was conducted. Revenue and profits generated, service uptake and product sales between the two groups were compared over a fixed period of 18 months.

Results: Eyelife ${ }^{\mathrm{TM}}$ members generated significantly higher professional fee revenue $(P<0.001), £ 153.96$ compared to $£ 83.50$, and profits $(P<0.001)$. Eyelife ${ }^{T M}$ members had a higher uptake of eye examinations $(P<0.001)$. The 2 groups demonstrated no significant difference in spectacle sales by volume $(P=0.790)$ or value $(P=0.369)$. There were also no significant differences in contact lens revenue $(P=0.337)$, although Eyelife ${ }^{\mathrm{TM}}$ members did receive a discount. The Eyelife ${ }^{\mathrm{TM}}$ group incurred higher contact lens costs $(P=0.037)$, due to a greater volume of contact lens purchases, 986 units compared to 582 .

Conclusions: Monthly payment plans improve loyalty among contact lens wearers, particularly service uptake and volume of lens purchases. Additionally the greater professional fees generated, render monthly payment plans an attractive business model and practice builder.

Keywords: Contact lenses, daily disposables, business model, profit, loyalty, professional fees 


\section{Introduction}

The UK contact lens market is mature, with only a relatively small yearly growth in wearers [1]. In total, there are around 3.7 million contact lens wearers in the UK [2], which represents $7.7 \%$ of the adult population and approximately $12 \%$ of adults requiring a refractive correction [1]. Contact lens sales form around $19 \%$ of the optical industry market share [3]. Changes to the Opticians Act made in 2005 allowed contact lenses to be supplied by other businesses, including supermarkets and Internet based companies. The Mintel Group Limited [3] suggests that online retailers capture $5 \%$ of the optical goods market. A recent survey commissioned by the Association of Contact Lens Manufacturers (ACLM) suggested that $10 \%$ of contact lens wearers purchase lenses online [4]; the Mintel Group Limited [3] also reports the same figure. Other non-UK based literature indicates that around $7 \%$ and up to $22.5 \%$ of contact lens wearers obtain their lenses from online sources [5][6][7][8]. Online suppliers have low operational costs and so are able to offer competitive prices. They may also be perceived as a more convenient mode of purchase. Despite this, the majority of contact lens wearers remain loyal to their eye care practitioners (ECP), with $66 \%$ to $70 \%$ of wearers purchasing lenses from their practitioner [5][8].

A number of concerns exist over wearers obtaining lenses from Internet suppliers. Dumbleton et al [5] revealed that wearers purchasing lenses from their ECP display greater compliance than wearers purchasing lenses elsewhere. Furthermore Wu et al [8] reported that wearers purchasing lenses from Internet suppliers are more likely to overlook aftercare visits. This cohort of patients has also been associated with a higher risk of developing serious complications, such as microbial keratitis [9]. Internet supply of contact lenses poses additional threats to optometric practices, by directly impacting sales and indirectly affecting the awareness of the practice by reducing footfall [3].

As the contact lens market further matures it is likely that the customer churn rate (the number of customers that defect from a company during a period) will increase, as is observed in the mobile telecommunications sector [10]. Additionally, deregulation of the sale and supply of contact lenses has made it easier for customers to 'shop around', and so optometric practices must work harder to retain existing customers. Improving customer loyalty and retention has been well studied. Literature reveals two important factors to improving customer loyalty. Firstly, customer satisfaction is the strongest component to creating loyal customers [11]. Secondly, factors that make switching service provider difficult. These are known as 'switching costs' [11] and include financial, social and psychological costs [12]. Therefore, a customer that is not completely satisfied with a product or service may still remain with the existing provider due to perceived switching costs [10]. These barriers can allow for fluctuations in service quality, which would otherwise result in customer defection [11]. However, customers tend to only consider switching when satisfaction falls below a critical level [11][13]. Optometric practices can offer incentives, such as discounts, to improve customer loyalty. For instance, a discount may be offered when an annual supply of contact lenses is purchased at the time of the examination, or there may be a discount on spectacles. In the UK, it is more 
common practice to offer discounts as part of a monthly payment plan. Monthly payment plans allow patients to pay for professional care and contact lens products on a monthly direct debit. Patients are contracted to purchase and receive a given supply of contact lenses, which is likely to improve compliance, as the patient has no incentive to overuse lenses or solutions. Monthly payment plans have proven popular among patients in the UK with $72 \%$ remaining on the direct debit plan after 3 years [14]. Although this may be related to perceived switching barriers associated with the contractual agreement, such as the effort of cancelling the monthly payment plan and sourcing a new contact lens provider. Also monthly payment plans offer a 'bundle' package making price comparisons less transparent.

The contact lens market is becoming increasingly competitive and although only a relatively small number of contact lens wearers choose to purchase lenses online, a future threat to optometric practices remains. Twenty-six per cent of contact lens wearers have considered purchasing contact lenses online [4] and $41 \%$ are likely to do so in the future [15]. There is a gap among peer-reviewed papers on the topic of contact lenses and customer loyalty, with most information presenting in non-peer reviewed articles such as market research reports and industry magazine articles. Monthly payment plans are thought to anecdotally improve customer loyalty, although there is limited tangible evidence.

This study aimed to gain an insight to the tangible effects of monthly payment plans on customer loyalty among contact lens wearers. The key focus of the study was behavioural loyalty, and more specifically the uptake of professional services and sales of contact lenses and spectacles by volume and value.

\section{Methods}

BBR Optometry Ltd, an independent practice based in Hereford offers a monthly payment plan, called Eyelife $\mathrm{T}^{\mathrm{TM}}$. This allows contact lens patients and spectacle wearers to arrange monthly direct debits for their professional care. The professional care package includes eye examinations, contact lens aftercares, contact lens refitting and emergency appointments. The care plan also includes supplementary tests such as fundus photography, ocular coherence tomography, corneal topography and dry eye assessments. Eyelife ${ }^{\mathrm{TM}}$ entitles the patient to unlimited number of appointments, and so if desired they could be reviewed sooner than their usual recall. Patients can combine Eyelife ${ }^{\mathrm{TM}}$ with any contact lens product. There are multiple tiers to Eyelife ${ }^{\mathrm{TM}}$, with varying prices entitling different levels of discounts on products (table 1). Patients that are not on the Eyelife ${ }^{\mathrm{TM}}$ monthly payment plan receive the same level of care and pay fees for each visit.

\section{Table 1}

A retrospective audit was conducted on daily disposable contact lens wearers at BBR Optometry Ltd. This study focused on daily disposable wearers as they have been shown to be more susceptible to Internet supply compared to other frequent replacement lenses [4]. A comparison of Eyelife ${ }^{\mathrm{TM}}$ members with non-members was carried out to assess influences on patient loyalty. The number of appointments (contact lens aftercare, eye examination and combined aftercare and eye examination), number of spectacle dispenses, average dispense value and contact 
lens sales (by volume and value) were recorded for both groups for a fixed 18 month period. Revenue, costs and net profit were categorised as professional service, spectacle or contact lens sales.

Subjects aged 19 to 69 and in full time daily disposable contact lens wear during a fixed period from June 2011 to November 2012 were included in the study. Eyelife ${ }^{\text {TM }}$ patients were only included if membership was continuous during the 18 month audit period. Exclusion criteria were as follows: diagnosis of diabetes mellitus or glaucoma or a positive family history of glaucoma, as these factors can influence the interval between examinations.

Electronic records of daily disposable contact lens wearers were analysed at the practice site. Ethical approval for this study was obtained from Aston University Ethics Committee. All data collected was tabulated in Microsoft ${ }^{\circledR}$ Excel $^{\circledR}$ (Microsoft Corporation, Redmond, Washington, USA). Statistical analysis was conducted using IBM $^{\circledR}$ SPSS $^{\circledR}$ Statistics 22 (IBM Corporation, Armonk, New York, USA) and Microsoft ${ }^{\circledR}$ Excel $^{\circledR}$. A Shapiro-Wilk test was conducted on all data sets to determine distribution normality. Statistical comparisons between Eyelife ${ }^{\mathrm{TM}}$ members and non-members were conducted using Mann-Whitney $U$ test and Independent T-Test for nonparametric and parametric data sets respectively. A P-value less than 0.05 was considered significant.

\section{Results}

Two hundred and sixty-eight patients at BBR Optometry Ltd were identified as current daily disposable contact lens wearers, however only 86 met the inclusion criteria for this study. Eighteen subjects were excluded as they were diagnosed with glaucoma or diabetes mellitus, or had a positive family history of glaucoma. The audit comprised of 38 Eyelife $^{\mathrm{TM}}$ members (11 male and 27 female) and 30 nonmembers (12 male and 18 female). The age ranged from 20 to 67 years for the Eyelife $^{\mathrm{TM}}$ group and was 20 to 69 years for the non-members group; mean age ( \pm SD) was $42.7 \pm 15.0$ years and $40.8 \pm 16.7$ years $(P=0.771)$ for the Eyelife ${ }^{T M}$ and nonmember group respectively. Both groups consisted of long-term contact lens wearers, on average wearing lenses for $12.0 \pm 5.5$ years and $10.3 \pm 4.3$ years $(P=1.231)$ for the Eyelife ${ }^{T M}$ and non-member group respectively. The most recent lens was fitted 8 years ago for the Eyelife ${ }^{\mathrm{TM}}$ group and 6 years ago for the nonmembers.

Figure 1

\section{Figure 2}

Figure 1 shows that Eyelife ${ }^{\mathrm{TM}}$ members have a greater uptake of eye examination services compared to non-members $(P<0.001)$. However, there were no significant differences found in the number of aftercare $(P=0.169)$ and combined appointments $(P=0.459)$ between the two groups. Eyelife ${ }^{\mathrm{TM}}$ members appear to generate much higher professional service revenue $(P<0.001)$ and profit $(P<0.001)$ compared to nonmembers (figure 2). The mean cost of providing professional services was significantly greater for the Eyelife ${ }^{\mathrm{TM}}$ group (figure 2 ) at $£ 70.83$ in contrast to $£ 56.24$ for the non-member group $(P=0.032)$. 


\section{Figure 5}

Figure 3 shows that only $36.8 \%$ of Eyelife ${ }^{\mathrm{TM}}$ members invested in spectacles during the 18 month audit period and only $33.3 \%$ for the non-member group. There was no significant difference $(P=0.790)$ in the mean number of spectacles purchased between the two groups (figure 3). Figure 4 demonstrates trends in average spectacle dispense values between the two groups. The mean average dispense values for the Eyelife ${ }^{\mathrm{TM}}$ group and non-member group were $£ 295.82$ and $£ 232.49$ respectively, and displayed no statically significant difference $(P=0.369)$. Eyelife members' generated, on average, $£ 311.01$ revenue and $£ 102.30$ profit in spectacles sales compared to $£ 262.79$ revenue and $£ 46.45$ profit from the non-member group. However revenue $(P=0.522)$, costs $(P=0.807)$ and profits $(P=0.435)$ generated through spectacle sales were not found to be statistically different between the two groups.

\section{Figure 6}

\section{Figure 7}

Figure 6 shows income generated from contact lens sales. Mean revenue generated through contact lens sales was similar between the two groups $(P=0.337)$. The mean profit generated through contact lens sales for the Eyelife ${ }^{\mathrm{TM}}$ group was $£ 168.21$ and $£ 214.22$ for the non-member group $(P=0560)$. Figure 6 reveals Eyelife ${ }^{T M}$ members to have significantly greater $(P=0.037)$ costs related to contact lens sales, $£ 301.27$

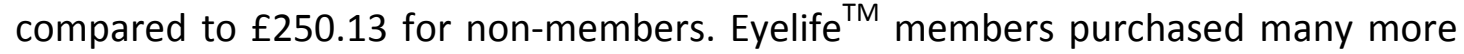
units of contact lenses as displayed in figure 7, particularly conventional and silicone hydrogel sphere lenses. The numbers of toric lens sales were similar (figure 7). The Eyelife $^{\mathrm{TM}}$ group bought almost twice as many units of contact lenses than the nonmember group, 986 compared to 582 units respectively. Figure 8 illustrates that both groups tended to purchase higher volumes of mid-value contact lenses, the non-member group more so (72\%) than the Eyelife ${ }^{\mathrm{TM}}$ group (43\%). Eyelife ${ }^{\mathrm{TM}}$ members had a more even distribution of lens purchases across the 3 price ranges, compared to the non-member group (figure 8). Figure 9 reveals the percentage of subjects that were fitted with low, mid and high-value contact lenses. The majority of subjects from both groups were wearing mid-value contact lenses. A higher percentage of Eyelife ${ }^{\mathrm{TM}}$ members, $24 \%$ compared to $10 \%$, are wearing low-value and high-value contact lenses compared to non-members (figure 9).

\section{Figure 8 here}

Figure 9 here

The overall mean revenue generated in the 18 -month period was $f 738.76$ for Eyelife $^{\mathrm{TM}}$ members and $£ 589.01$ for non-members $(\mathrm{P}=0.026)$. The overall mean profit produced by Eyelife ${ }^{\mathrm{TM}}$ members was $£ 289.02$ compared to $£ 235.54$ for nonmembers $(P=0.231)$. 


\section{Discussion}

Contact lens wearers are seen as high net worth clients at many optometric practices [16]. The aim of this study was to investigate the relationship between monthly payment plans and customer loyalty among daily disposable contact lens wearers.

\section{Professional service uptake}

Eyelife $^{T M}$ members have a more frequent uptake of eye examinations compared to non-members (figure 1). Eyelife ${ }^{\mathrm{TM}}$ members are encouraged to have more regularly eye examinations, every year, as opposed to every 2 years. This supports the notion that monthly payment plans "bring patients back into the practice more regularly" [17]. The Eyelife ${ }^{\mathrm{TM}}$ monthly payment plan has no limit to the number of services a patient wishes to book. This may explain the higher amount of services attended by Eyelife ${ }^{\mathrm{TM}}$ members, particularly those prepared 'to get their monies worth'. Also the concept of unlimited appointments may lead Eyelife ${ }^{T M}$ members to become less hesitant to arrange additional unscheduled appointments for minor complications or concerns, lowering the risk of developing serious complications. Dumbleton et al [5] revealed that patients purchasing contact lenses from their ECP tend to return more frequently for examinations compared to patients obtaining lenses elsewhere. Interestingly all Eyelife ${ }^{\mathrm{TM}}$ subjects had purchased contact lenses from BBR Optometry Ltd, whereas only $90 \%$ of the non-member group had acquired lenses directly from the practice. The number of contact lens aftercare and combined appointment visits between the two groups were similar, and so the Eyelife ${ }^{\mathrm{TM}}$ plan fails to encourage more frequent contact lens checks.

The most popular appointment type amongst both groups is the combined type, with both groups on average attending for at least one combined appointment during the 18-month audit period (figure 1). Many subjects also attended an aftercare only appointment (figure 1). Therefore on average all subjects attended some form of contact lens aftercare at least once during the 18-month period, suggesting all subjects were compliant towards the recommended minimum 12month interval between contact lens check-ups.

The Eyelife ${ }^{\mathrm{TM}}$ group generated far higher professional service revenue and profits (figure 2), which were not only statistically significant, but will also have a positive impact on the business. Efron et al [18] calculated the annual revenue from contact lens professional fees to be $£ 150$. This was based on the first 12 months of contact lens wear. The current study suggests that professional fees generated from contact lens wearers are less than this, particularly from wearers not on a monthly payment plan. However the current study is based on established wearers rather than the first 12 months of contact lens wear, which would include initial fitting appointment fees.

Figure 2 also demonstrates a statistically significant difference in the costs associated with providing professional care between the 2 groups. This is likely related to the difference in service uptake as the Eyelife ${ }^{\mathrm{TM}}$ group booked more appointments in total.

\section{Spectacle sales}


235 Eyelife $^{\mathrm{TM}}$ members attend more frequently for eye examinations creating an ideal opportunity to supply spectacles and sunglasses since $80 \%$ of contact lens wearers also wear spectacles [17]. However this study found relatively low spectacle purchases amongst both groups of daily disposable contact lens wearers. Over $60 \%$ of patients in both groups did not purchase any spectacles (figure 3), despite $94.7 \%$ and $86.7 \%$ of Eyelife ${ }^{\mathrm{TM}}$ members and non-members attending at least one eye examination or combined appointment during the audit period. This study implies that contact lens wearers have a low spectacle dispense conversion rate compared to spectacle wearers; $44 \%$ of spectacle wearers purchased new spectacles in the last 12 months and 35\% purchased a pair 1-2 years ago [3]. However, it is possible that these patients may have purchased spectacles elsewhere. Eyelife ${ }^{\mathrm{TM}}$ members are entitled to discounts on spectacles and so it would be assumed that Eyelife $\mathrm{T}^{\mathrm{TM}}$ members would choose to purchase spectacles from the practice rather than shopping elsewhere.

The mean number of spectacle sales and average spend of spectacles were similar between the two groups (figures 3 and 4). Therefore the monthly payment plan and accompanying discounts failed to entice Eyelife ${ }^{\mathrm{TM}}$ members to purchase more spectacles and upgrade to higher value products. Hence this monthly payment plan designed for contact lens wearers did not generate significantly greater spectacle sale revenue or profits compared to the non-member group.

\section{Contact lens sales}

Keynote Limited [1] reported that the annual spend on daily disposable contact lenses was around $£ 200$ to $£ 400$, and Efron et al [18] calculated annual spend to be f378.98. The current study shows a higher spend on contact lenses (figure 6), by both groups, as this audit encompassed an 18-month period rather than 12 months. However if values reported in published literature [1][18] are projected to represent an 18-month period, they become comparable. Therefore it seems reasonable to assume that subjects of this study represent normal daily disposable contact lens purchase behaviour.

Both groups produced similar levels of revenue and profit from contact lens sales (figure 6). However the cost of lens supply was significantly different, with the Eyelife $^{\mathrm{TM}}$ group incurring more costs, $£ 307.27$ compared to $\mathrm{f250.13}$ (figure 6). This finding could be the result of greater volume of contact lens sales displayed by the Eyelife $^{\mathrm{TM}}$ group or greater value of contact lens sales. The value of contact lens purchases by both groups was similar (figure 8). Both groups of daily disposable wearers favoured mid-value lenses (figure 8). The calculated cost per unit (total contact lens cost divided by total units sold) was found to be $f 11.61$ for the Eyelife ${ }^{\mathrm{TM}}$ group and $\mathrm{f} 11.60$ for the non-members. Therefore monthly payment plans do not influence the value of contact lens purchases. The greater costs incurred is the likely result of a substantially higher volume of contact lens purchases by the Eyelife ${ }^{\mathrm{TM}}$ group; 986 units compared to 582 units (figure 7). Eyelife ${ }^{\mathrm{TM}}$ members receive a discount towards any contact lens purchases (table 1) and so, despite a greater volume of sales the mean revenue appears deflated, and consequently renders a lower profit margin (figure 6). 
It could be argued that the distribution of refractive error amongst the two groups may influence the volume of contact lens sales. Both groups consisted of full time wearers, however a patient with a higher refractive error might be more proactive in keeping on top of their lens supply. Additionally those with higher refractive errors may wear lenses for longer hours and so may have been fitted with newer materials such as silicone hydrogel. Figure 7 shows Eyelife members to purchased more silicone hydrogel lenses than non-members. The refractive errors for study subjects were reviewed. The best sphere (BS) contact lens prescription was recorded for each eye and then averaged (excluding direction, minus or plus). The average BS for Eyelife $^{\mathrm{TM}}$ members was 4.33 , and was found to be significantly greater $(\mathrm{P}=0.039)$ than 3.64 for non-members. This factor may have influenced patients into selfselecting onto the Eyelife ${ }^{\mathrm{TM}}$ plan and purchasing a greater volume of contact lenses. Alternatively this may be a direct result of the discount received by Eyelife ${ }^{\mathrm{TM}}$ members or due to switching barriers associated with monthly direct debits.

\section{Revenue and profit}

Monthly payment plans allow realistic fees to be charged for professional services, creating less reliance on product sales to produce profit [19]. This allows for a more sustainable business model, particularly in such a competitive market. This study found that of all the revenue streams, professional service revenue demonstrated a statistically significant difference. The Eyelife ${ }^{\mathrm{TM}}$ members generated almost double professional service revenue (figure 2) and thus produced significantly greater overall revenue. However, there was no significant difference in the overall profit generate by the two groups. Therefore despite producing more revenue, monthly payment plans do generate more profitable. This is due to the greater costs incurred through a higher volume of discounted contact lens sales (figure 6).

This study indicates that charging appropriately for professional services provides the opportunity to supply products at competitive prices and will encourage contact lens patients to remain loyal to the practice. Additionally a pricing structure with a higher professional service fee and lower commodity cost is advantageous as incomes generated from services are VAT exempt. Eyelife ${ }^{\mathrm{TM}}$ members purchased significantly more contact lenses (figure 7). It is uncertain whether this was the result of competitive prices or other factors such as refractive error, switching costs and customer satisfaction. Offering competitive prices may also improve compliance and encourage contact lens wearers to refrain from overusing lenses [5][6].

\section{Limitations}

There are a number of limitations to this study. Study subjects consisted of a relatively small sample. Post hoc statistical power calculation of the presented sample size is $67 \%$. The greater the statistical power, the more likely the null hypothesis is rejected correctly. The ideal statistical power is $80 \%$; for which this study would require a sample size of 95 subjects, to detect a difference of $f 150$ in overall mean revenue at a significance level of 0.05 . The sample also mostly comprised of female patients. A recent survey suggested that females are less likely to purchase contact lenses from Internet based companies [4]. The majority of 
subjects were long-term customers of the practice, which may also influence customer loyalty. Additionally long-term customers tend to perceive higher switching barriers than short-term customers [20][21]. This study was isolated to daily disposable contact lens wearers and also to a single optometric practice, and so the results of this study may not portray other contact lens populations.

\section{Conclusion}

This study assessed the influence of monthly payment plans on customer loyalty among daily disposable contact lens wearers. Monthly payment plan members purchased a higher volume of contact lenses and attended for more professional services. Overall monthly payment plan members were found to demonstrate greater practice loyalty, although there was little influence on the number and value of spectacles sales. In addition this study suggests that monthly payment plans offer a more sustainable business model by generating greater professional service revenue and thus relying less on product sales to generate income. Such a model that steers away from loss leading allows products to be priced competitively. Monthly payment plans also align well with other developments in optometry, such as therapeutic prescribing. Therapeutic prescribing services may not lead to product sales but will allow contact lens complications to be managed in-house, further enhancing loyalty and professional value. However uptake of the service and increase in appointments would need to be considered within the monthly payment plan fee. Further investigation is required to establish whether similar trends occur among different lens modalities, new contact lens wearers, new patients and different types of optometric practices.

\section{References}

[1] Key Note Limited, Market Assessment 2010: Opticians \& Optical Goods; $5^{\text {th }}$ ed. Baxter, J (Eds), Key Note Ltd, Middlesex, UK, 2010.

[2] The ACLM Contact Lens Year Book 2013: ACLM Market Report 2012. Kerr, C and McParland, M (Eds): The Association of Contact Lens Manufacturers (ACLM), Wiltshire, UK, 2013.

[3] Mintel Group Limited, Optical Goods Retailing - UK. Mintel Group Ltd, London, UK (2010) [4] Ewbank. A (2013) Understanding the CL consumer: Part 1 - Buying habits and customer loyalty. Optician; 6400(245): 38-40

[5] Dumbleton. K, Richter. D, Bergenske. P and Jones. L. W (2013) Compliance with Lens Replacement and the Interval between Eye Examinations. Optom Vis Sci; 90: 351-358 [6] Dumbleton. K, Woods. C. A, Jones. L. W, Fonn. D (2013a) The impact of contemporary contact lenses on contact lens discontinuation. Eye Contact Lens; 39: 92-98

[7] Fogel. J and Zidile. C (2008) Contact lenses purchased over the Internet place individuals potentially at risk for harmful eye care practices. Optometry; 79: 23-35

[8] Wu. Y, Carnt. N and Stapleton. F (2010) Contact lens use profile, attitudes and level of compliance to lens care. Cont Lens Anterior Eye; 33: $183-188$

[9] Stapleton. F, Keay. L, Edwards. K, Naduvilath. T, Dart. J. K. G, Brian. G and Holden. B. A (2008) The Incidence of Contact Lens-Related Microbial Keratitis in Australia. Ophthalmology; 115(10): 1655-1662

[10] Kim. M-K, Park. M-C, Jeong. D-H (2004) The effects of customer satisfaction and switching barrier on customer loyalty in Korean mobile telecommunications services. Telecommun Policy; 28: 145-159 
[11] Jones. M. A, Mothersbaugh. D. L, Beatty. S. E (2000). Switching Barriers and Repurchase Intentions in Services. J Retailing; 76(2): 259-274

[12] Fornell. C (1992) A national customer satisfaction barometer: The Swedish experience. J

380 Marketing; 56(1): 6-21

381 [13] Colgate. M, Tong. V. T-U, Lee. C. K-C, Farley. J. U (2007) Back From the Brink: Why Customers Stay. J Serv Res-Us; 9(3): 211-228

[14] Bennett. C (2012) Comment: Direct proof of patient loyalty. Optician; 6378(244): 10

[15] Optometry Today (2013) News: CL Users Looking Online. Optometry Today; 10(53): 6

[16] Ritson. M (2006) Which patients are more profitable? Contact Lens Spectrum; March

386 2006: 38-42

387 [17] Optometry Today (2012) AGM: CLs 'could be key'. Optometry today; 11(52): 26

[18] Efron. S. E, Efron. N, Morgan. P. B and Morgan S. L (2012) A theoretical model for

391 [19] Brogan. R (2011) New Focus 'Web seminar takes stock'. Optician; 241(6287): 8 [20] Liu. C-T, Guo. Y. M, Lee. C-H (2011) The effects of relationship quality and switching barriers on customer loyalty. Int J Inform Manage; 31: 71-9 Marketing. J Marketing; 58: 20-38 


\begin{tabular}{|c|c|c|c|c|}
\hline $\begin{array}{l}\text { Monthly Payment } \\
\text { Plan }\end{array}$ & $\begin{array}{l}\text { Monthly Direct } \\
\text { Debit }\end{array}$ & $\begin{array}{l}\text { Spectacle } \\
\text { Discount }\end{array}$ & $\begin{array}{l}\text { Sunglasses } \\
\text { Discount }\end{array}$ & $\begin{array}{l}\text { Contact Lens } \\
\text { Discount }\end{array}$ \\
\hline Eyelife $^{\mathrm{TM}}$ Classic & $f 8.00$ & $20 \%$ & $15 \%$ & $16 \%$ \\
\hline Eyelife $^{\mathrm{TM}}$ Optimum & £9.95 & $20 \%$ & $20 \%$ & $16 \%$ \\
\hline Eyelife $^{\mathrm{TM}}$ Select & f11.85 & $25 \%$ & $25 \%$ & $16 \%$ \\
\hline Eyelife $^{\mathrm{TM}}$ Elite & f14.50 & $35 \%$ & $35 \%$ & $16 \%$ \\
\hline
\end{tabular}

Table 1. A summary of monthly payment plans offered to contact lens wearers at BBR Optometry Ltd. 
Figure 1

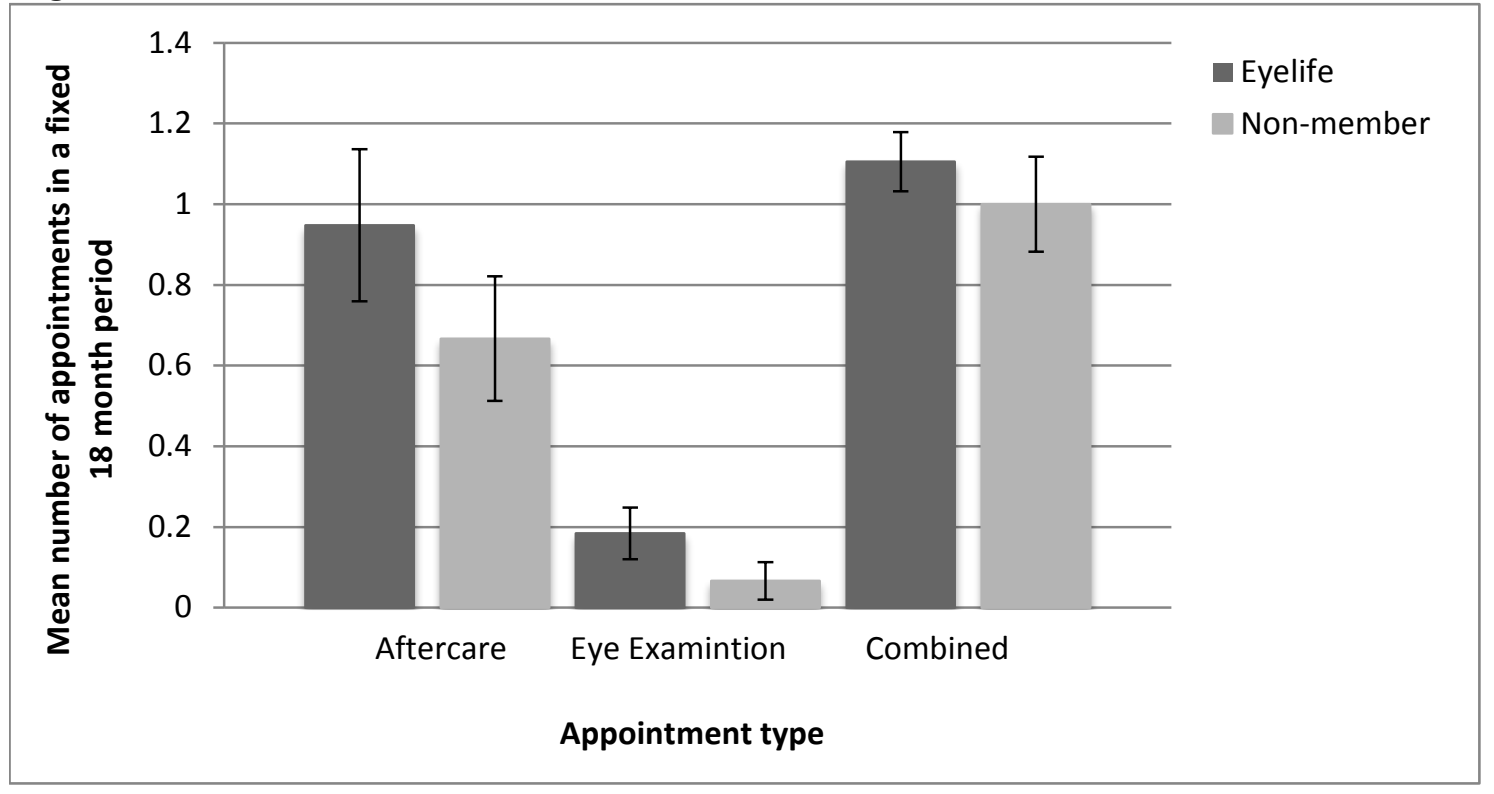

Figure 4

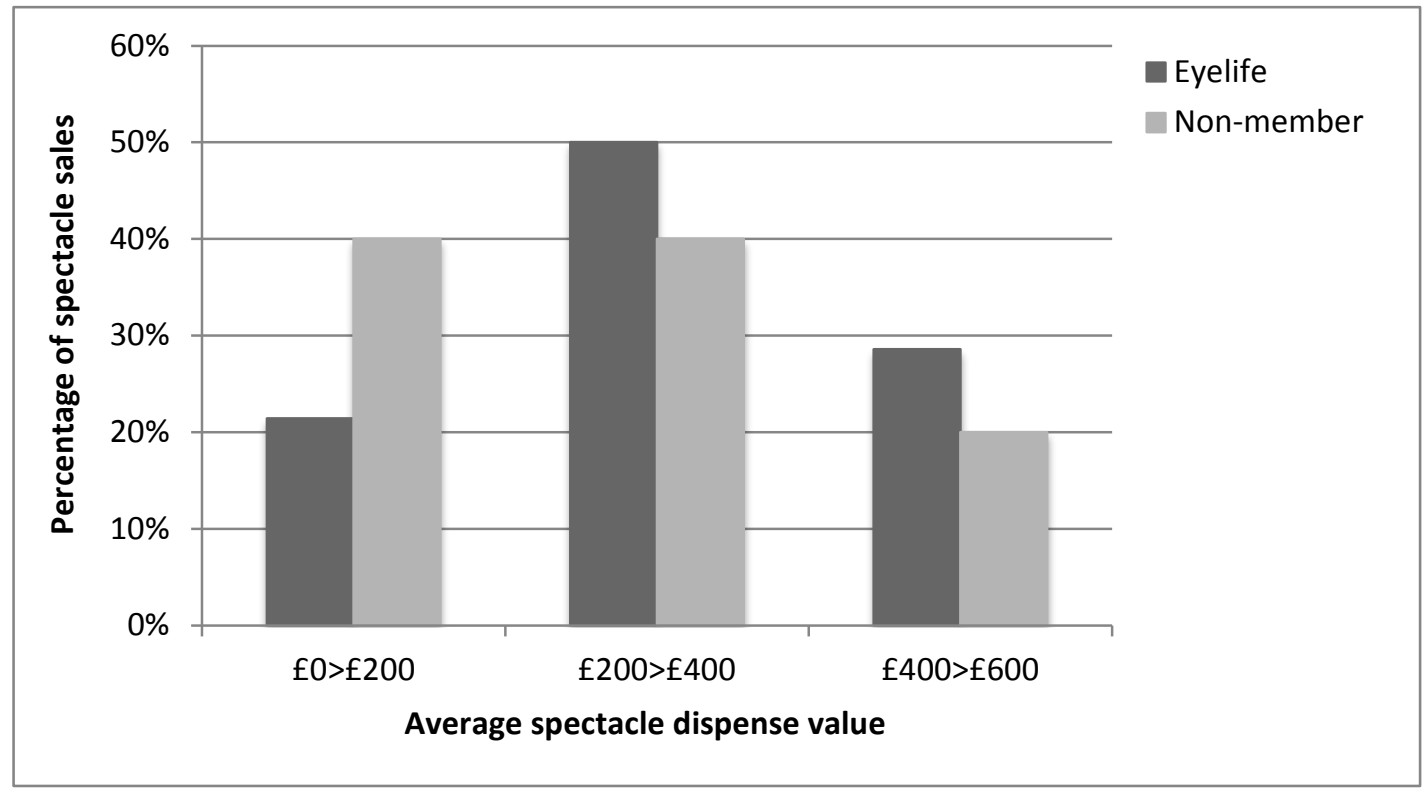

Figure 7 




Figure 9

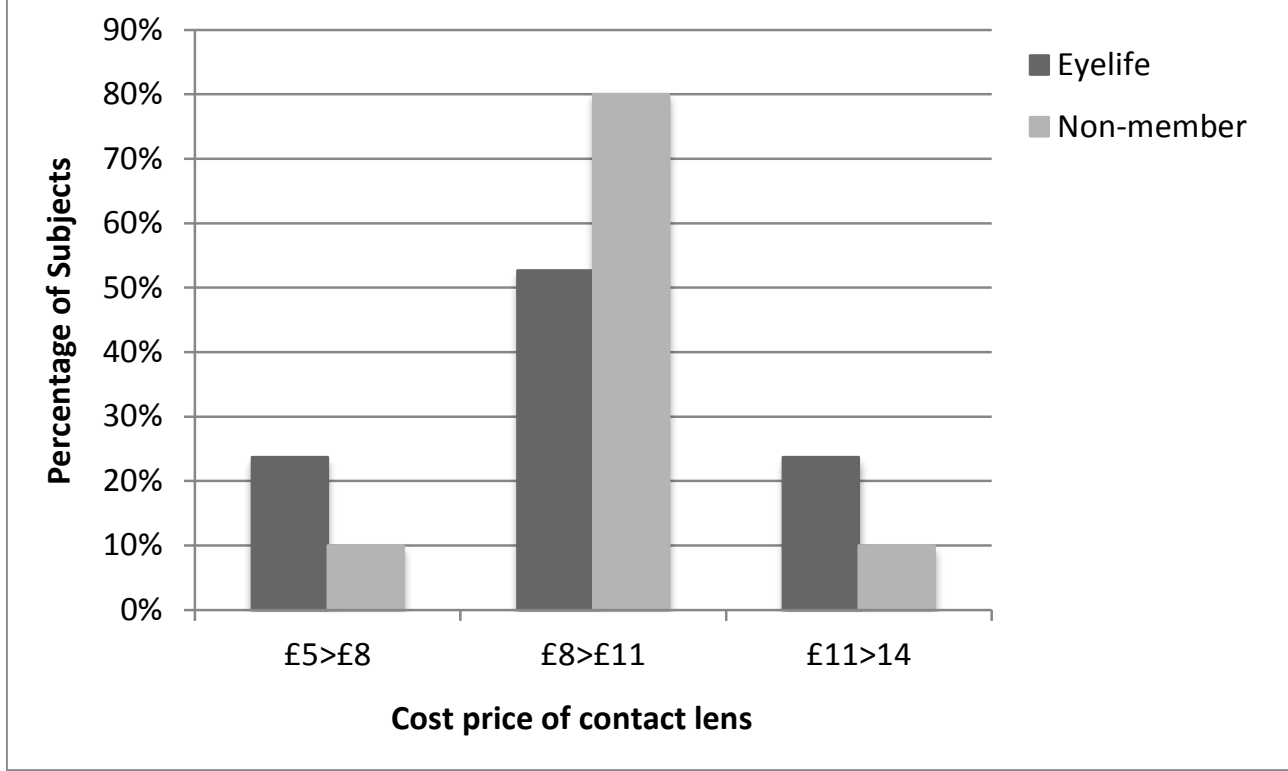


Figure 2

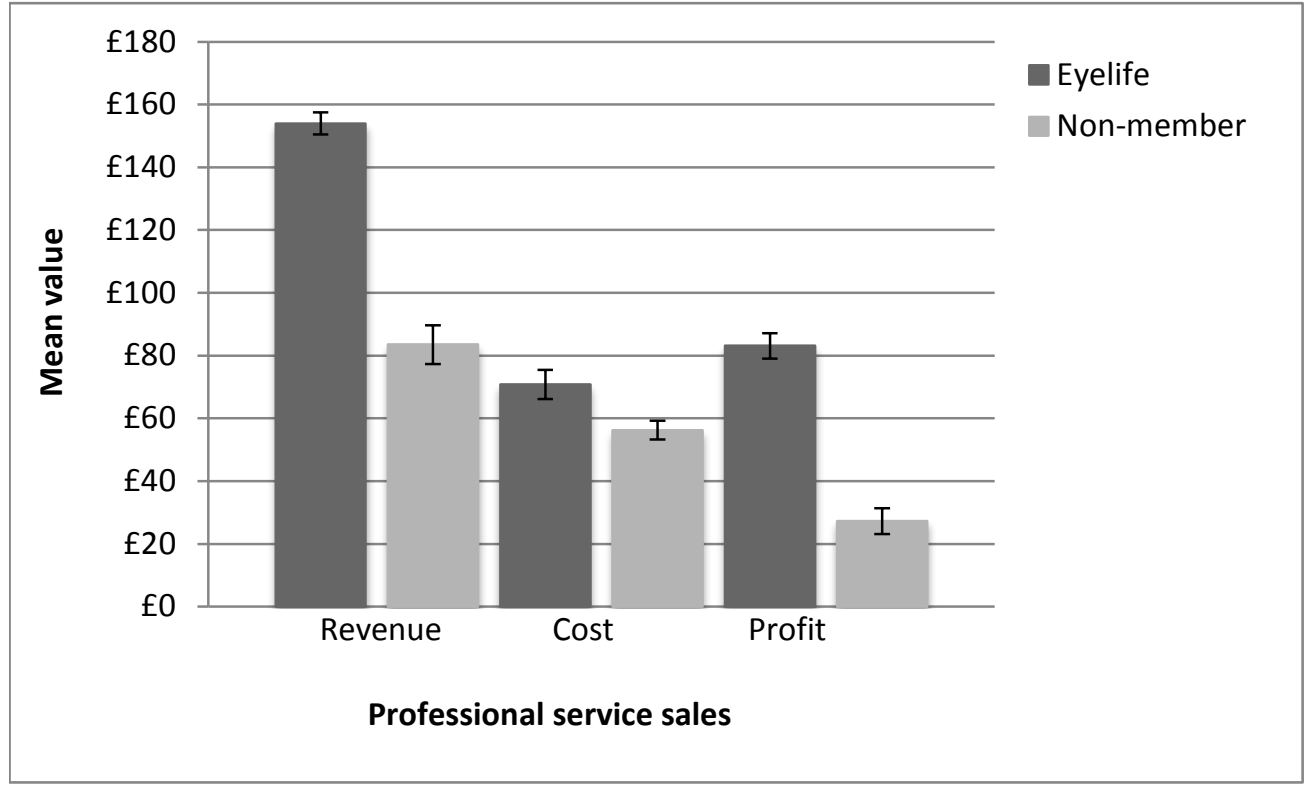

Figure 5

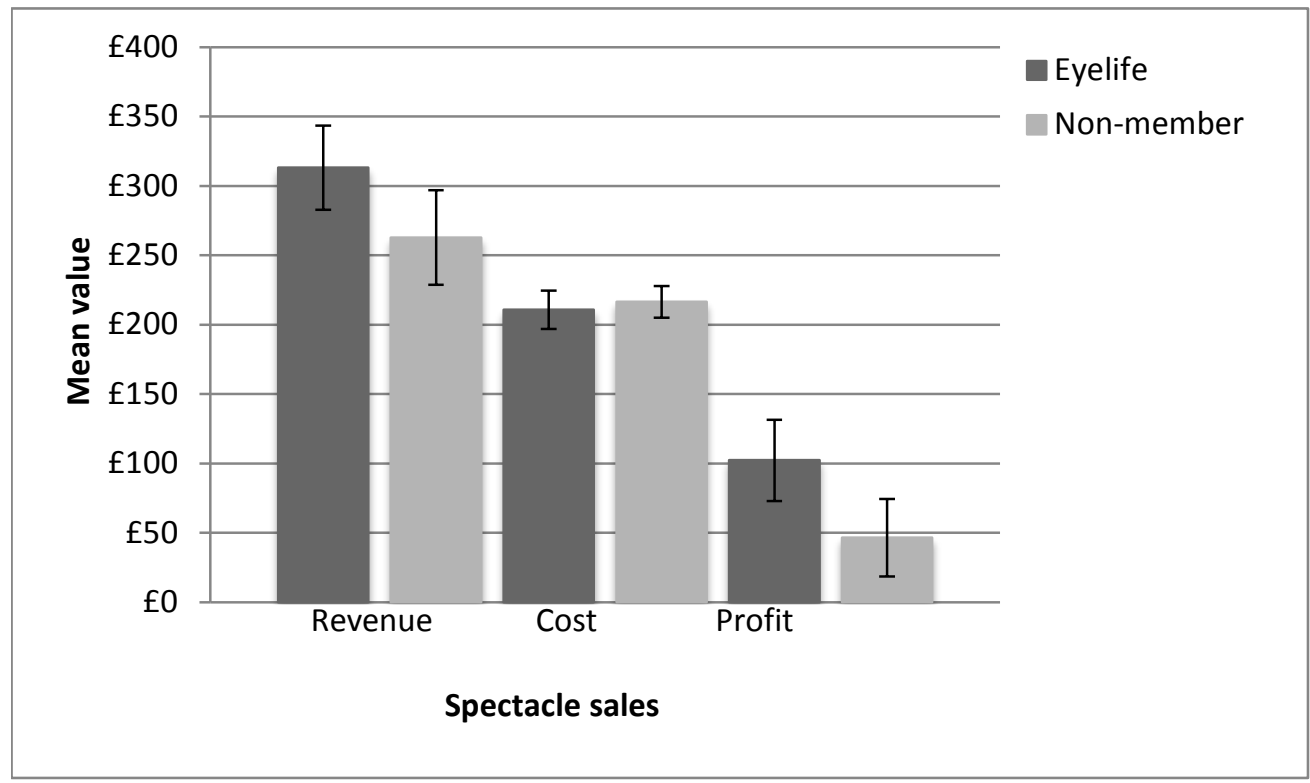


Figure 8

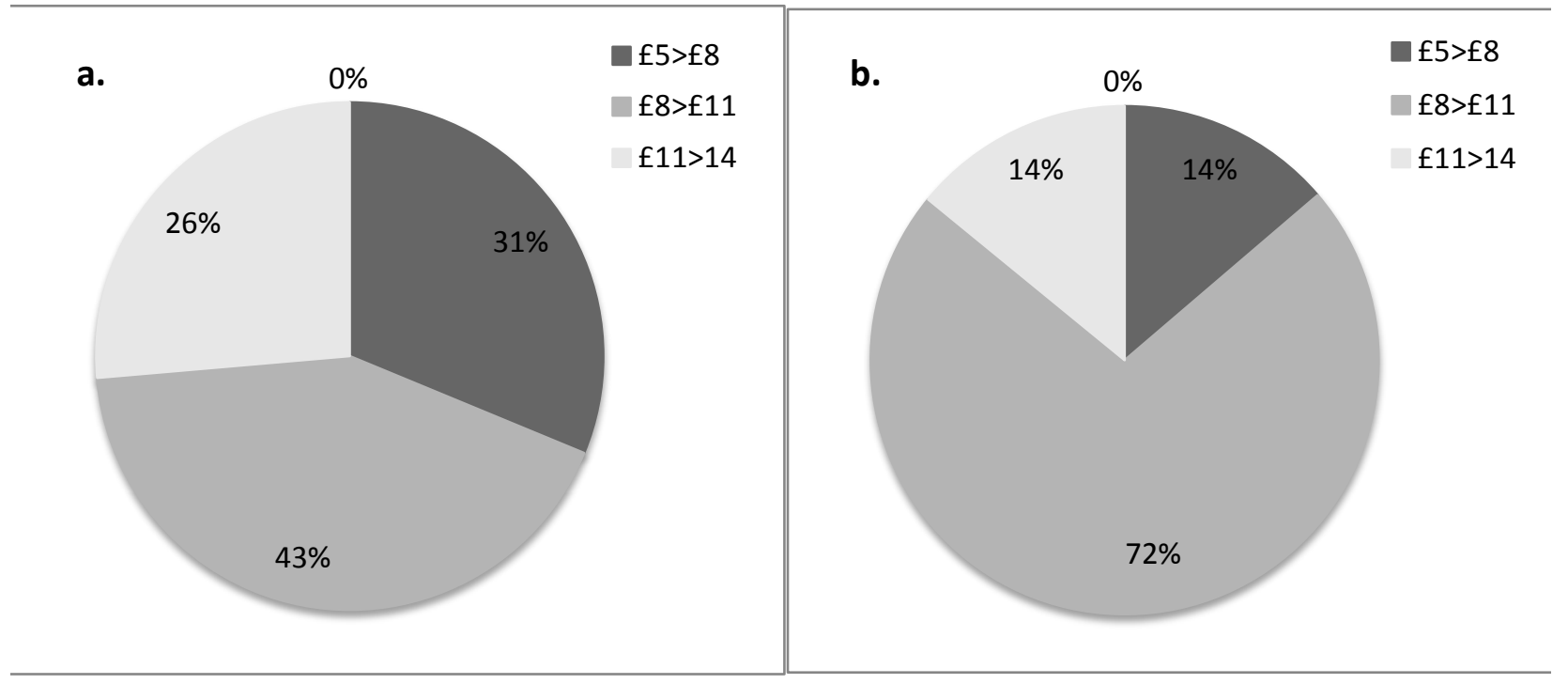


Figure 3

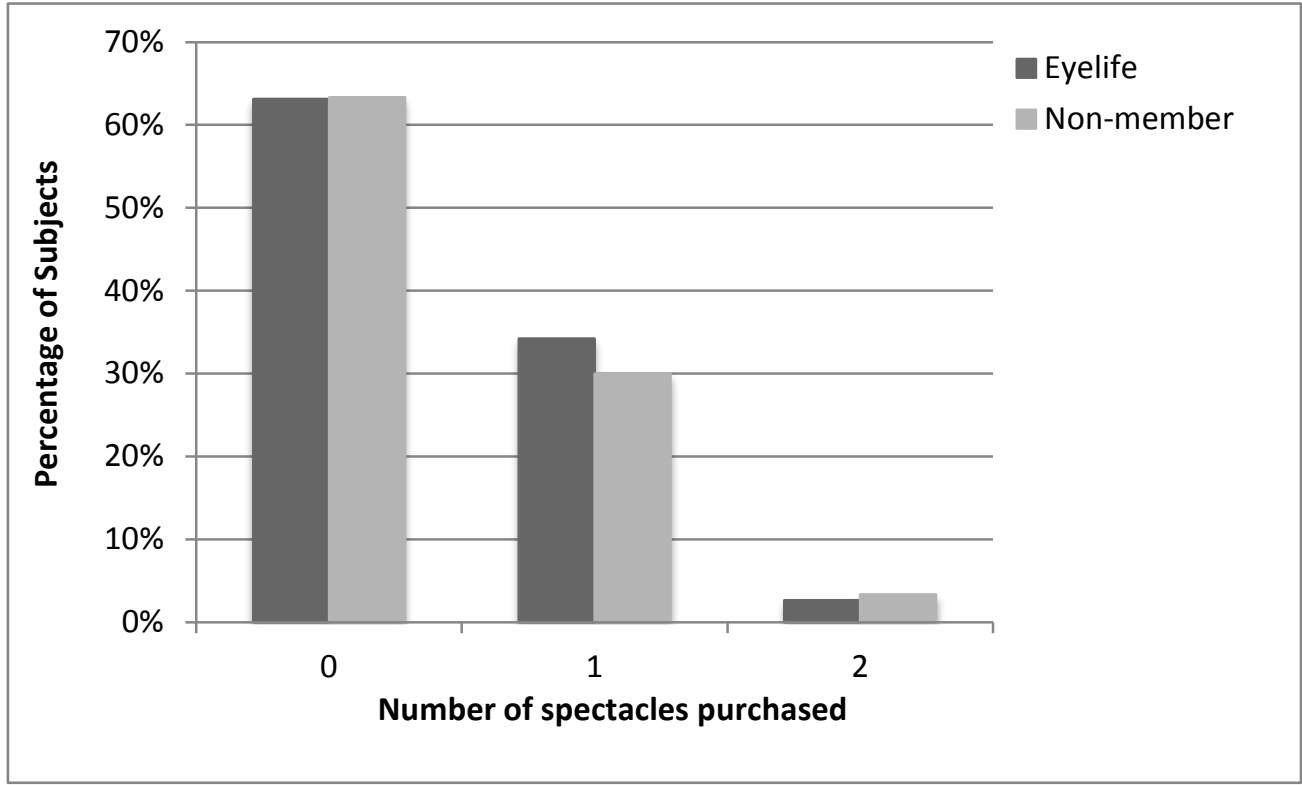

Figure 6

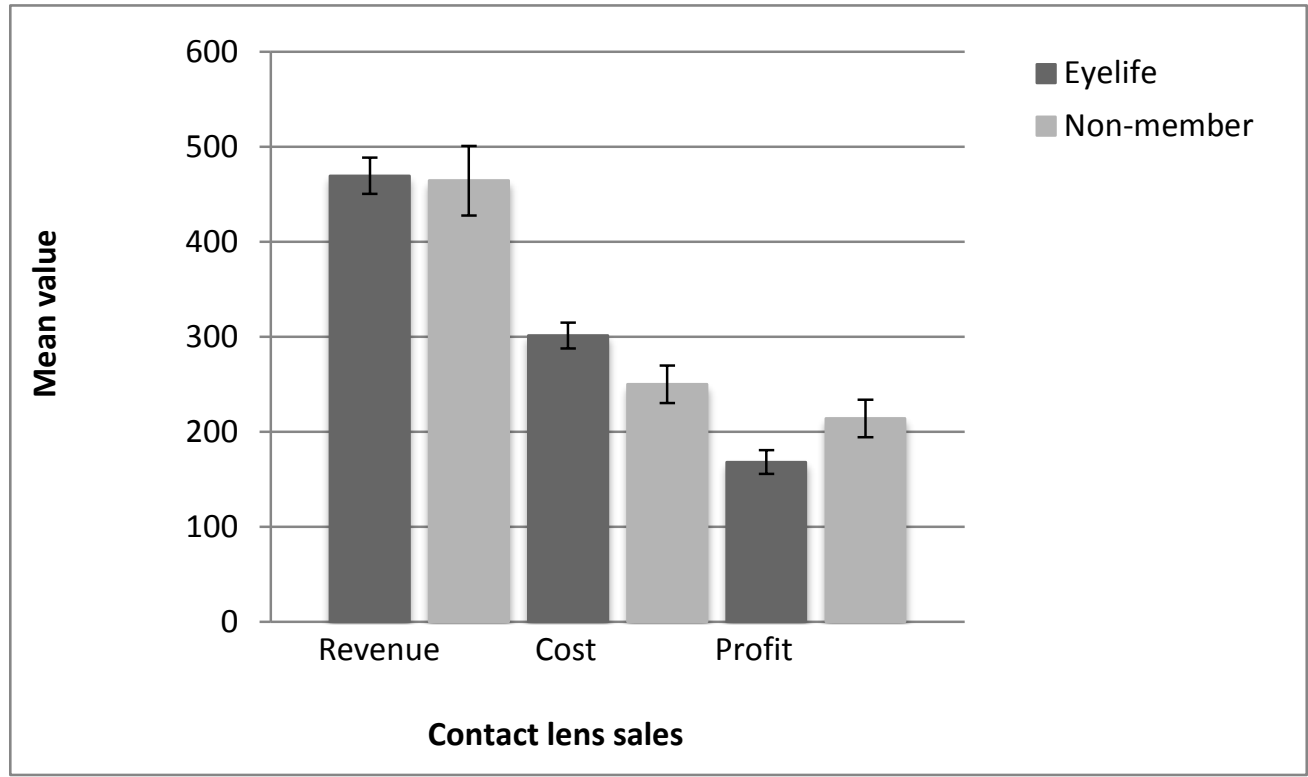


Figure 1. A bar chart to represent the mean number of appointments attended by the EyelifeTM group and non-member group during 18 months

Figure 2. Mean revenue, cost and profit generated from professional services sales

Figure 3. The number of spectacles purchased by EyelifeTM group and non-members during June 2011 to November 2012

Figure 4. A bar chart to show the mean value of spectacles purchased by both groups

Figure 5. The mean revenue, cost and net profit generated from spectacle sales for EyelifeTM members and non-members

Figure 6. A bar chart to show the mean revenue, cost and profit generated by contact lens sales by Eyelife members and nonmembers

Figure 7. A bar chart to display the units of contact lenses purchased by both groups

Figure 8. A pie chart to show the cost price distribution of lens units purchased by both groups (a) represents EyelifeTM members and (b) represents the non-member group

Figure 9. A bar chart to show the percentage of subjects fitted with each type of lens (categorised by cost price). 